\title{
Potential protective effects of silk fibroin against ethanol induced gastric ulcer
}

\author{
Aslı Aykaç 1,*, Buse Karanlık ${ }^{2}$, Ahmet Özer Şehirli ${ }^{3}$ \\ 1 Near East University, Department of Biophysics, Faculty of Medicine, Lefkoşa, Turkish Republic of Northern \\ Cyprus. \\ 2 Near East University, Department of Histology and Embryology, Vocational School of Health Sciences, Lefkoşa, \\ Turkish Republic of Northern Cyprus. \\ 3 Near East University, Department of Pharmacology, Faculty of Dentistry, Lefkoşa, Turkish Republic of Northern \\ Cyprus. \\ * Correspondence: aykacasli@yahoo.com (A.A.); Tel: +90392 6751000; ORCID No: 0000-0002-4885-5070.
}

Received: 2 August 2017 / Revised: 12 September 2017 / Accepted: 20 September 2017

\begin{abstract}
Ulcers that develop due to alcohol consumption are frequently confronted. The aim of this study was to investigate the protective effects of silk fibroin on the pro-apoptotic and anti-apoptotic protein expression levels on ethanol induced-ulcer models in rats. For three consecutive days, orogastrically either silk fibroin or saline were given to rats. On the 4th day, animals were deprived of food but allowed free access to water for $24 \mathrm{~h}$ before the experiment. While control groups were treated with only physiological saline, the ulcer groups were treated orally either with saline or silk fibroin groups. For ulcer induction, $1 \mathrm{ml}$ of absolute ethanol by gavage were given to both group. Firstly, intracardiac blood was taken at $60 \mathrm{~min}$ of $\mathrm{EtOH}$ or saline administration and immediately animals were decapitated. In blood samples, the amount of TNF- $\alpha$, IL-1 $\beta$ were analysed whereas in stomach tissues, the levels of MDA, GSH, and MPO activity and the expression levels of bcl-2, Bax, caspase-3 and -9 were determined. In ulcer groups, the amount of TNF- $\alpha$, IL-1 $\beta$, MDA, MPO, caspase- 3 and caspase- 9 were found to be significantly higher compared to control groups whereas in GSH, Bcl-2/Bax were found to be lower $(\mathrm{p}<0.005)$. In treatment groups it is observed that silk fibroin recovers the amount of TNF- $\alpha$, IL 1- $\beta$, MDA, MPO, GSH, caspase- 3 , caspase-9, and Bcl2 Bax. In conclusion, for the treatment of the gastric ulcer SF thought to be very efficient therapeutic agent.
\end{abstract}

KEYWORDS: Ethanol; gastric mucosal injury; silk fibroin; apoptosis; cytokines; ulcer.

\section{INTRODUCTION}

Continuous exposure to noxious factors like Helicobacter pylori (H. pylori) and use of alcohol and nicotine negatively effects the structural integrity and function of the protective mucosal barrier. When the barrier is broken by the aggressive offensive factors; the increase of free oxygen radicals which is known to be an important factor in the activation of inflammatory pathways, the gastric leads to mucosal damage by allowing a back diffusion of gastric acid into the mucosal layers, forming a gastric ulcer and necrosis [1]. Healing of gastric ulcer involves cell migration, proliferation and epithelial regeneration at the ulcer base that is mainly coordinated by a variety of an apoptotic factors, and cytokines [2,3]. Ulcers that develop due to alcohol consumption are frequently confronted. Intensively taken alcohol leads to mucosal edema and inflammatory cell infiltration forming acute and hemorrhagic gastric erosion. The mechanisms of mucosal injury due to alcohol consumption is poorly understood today. Increase in free oxygen radicals is known to be a factor in such diseases like ischemia/reperfusion injury, sepsis, colitis, ulcer, etc., by causing lipid peroxidation, protein oxidation and apoptosis.

Excessive intake of ethanol (EtOH) is the precondition of acute and hemorrhagic gastric erosions. It is known that, intragastrically administered $\mathrm{EtOH}$ quickly penetrates the gastrointestinal mucosa leading

How to cite this article: Aykaç A, Karanlık B, Şehirli AÖ. Potential protective effects of silk fibroin against ethanol induced gastric ulcer. Marmara Pharm J. 2018; 22 (2): 163-172. 
to deplation of cells, membrane damage and erosion. Many studies were conducted dealing with the mechanism of ulcer healing by using EtOH ulcer model which highly resembles human ulcers in terms of both pathological features and healing mechanisms. Therefore, ulcer model is commonly used to develop novel therapeutic agents that could potentially prevent ulcer deterioration or increased ulcer healing $[4,5]$. Although considerable research focused on preventing ulcer progression, the mechanism of cell death was not clearly understood and extensively studied. Apoptosis is a form of programmed cell death where the association of this cell death mechanism is not known clearly whether it has role in preventing ulcer progression in ulcer rat model or not.

Silk fibroin (SF) derived from silkworm is a very importrant protein-polymer for biomedical applications. The useful features of this polymer are ability to promote tissue formation [6, 7]. biodegradability $[8,9]$ and its interactions with cells [10,11]. Due to its excellent mechanical property, hemostatic properties, non-cytotoxicity, low antigenicity and non-inflammatory characteristics SF plays major role in tissue engineering and regenerative medicine [10-13]. Silk fibroin has also been identified as a biomaterial for skin repair due to its homeostatic properties, and permeability to oxygen and water vapor [14-16]. Although there are no data showing association of Silk fibrion effects on ulcer model there are studies showing that silk fibroin had safe and positive effects in wound healing in animal models [17, 18]. Therefore, in this study it is thought that Silk fibrion might have important role in ulcer treatment in rat model.

Lack of translational evidence in literature has hampered silk fibroin's clinical application for tissue repair. As a result of these findings, the current study was designed to investigate whether and to what extent silk fibroin would provide protection against ethanol-induced gastric mucosal ulcer by determining the presence of gastric injury using biochemical and molecular parameters. Therefore, in this study translational potential of the SF was investigated for this tissue repair by performing preclinical studies to fully assess its safety and effectiveness.

\section{RESULTS}

\subsection{Results related to serum}

As can be seen in Figure 1a and b, plasma levels of pro-inflammatory cytokines (TNF- $\alpha$ and IL-1 $\beta$ ) were significantly higher in the ulcer group than those of the control group $(p<0.001)$. The increased values in saline-treated ulcer group was significantly reduced approaching to the control values with the silk fibroin treatment $(\mathrm{p}<0.001)$.

\subsection{Results Related to Tissues}

\subsubsection{Macroscopic analysis}

As shown in Figure 1c, ethanol application to the previously saline-treated animals leads to extensive gastric lesions where ulcer index was found to be significantly higher as compared to control rats without any lesion $(P<0.001)$. However, application of SF (body wt) $(100 \mathrm{mg} / \mathrm{kg} / \mathrm{po})$ for 3 days before ulcer induction significantly decreased the ulcer index $(\mathrm{p}<0.001)$.

a)

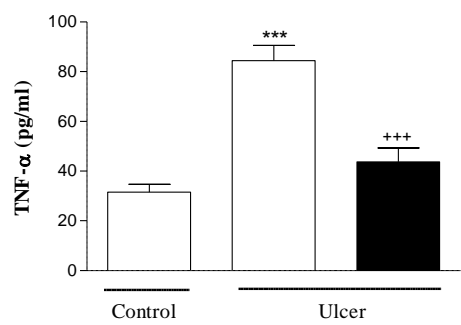

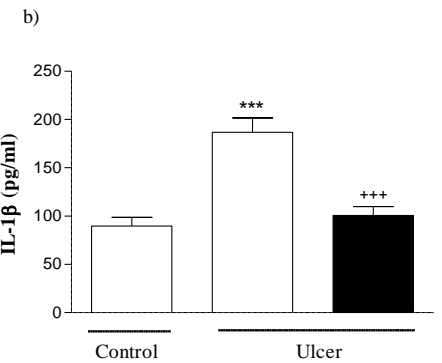

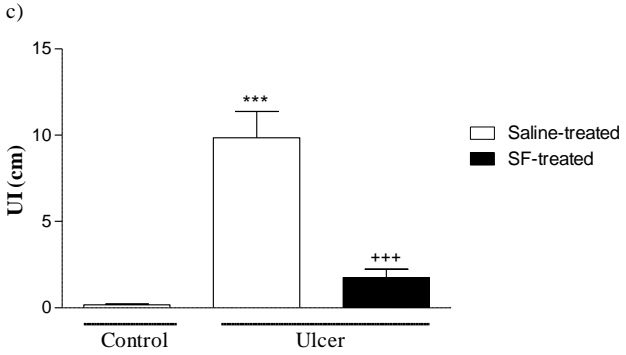

Figure 1. The levels of serum a) TNF- $\alpha$,b) IL-1 $\beta$ and c) Ulcer index (UI) of experimental groups in a rat model of ulcer. Each group consists of 6 animals. SF; silk fibroin.

${ }^{* * *} p<0.001$ Comparisons according to control group ${ }^{+++} p<0.001$ Comparisons according to ulcer group. 


\subsubsection{Levels of MDA, GSH and MPO activity assays}

When malondialdehyde (MDA) levels were examined, a significant increase was found in the group of ulcers performed in the stomach tissue according to the control group and SF administration significantly reduced this elevation in MDA levels as shown in Figure 2a.

Glutathione (GSH) levels in gastric mucosa were found to be lower in the ulcer group than in the control group. This reduction was found to be significantly inhibited in the group of ulcers treated with SF as can be seen in Figure $2 b$.

As can be seen in Figure 2c, Myeloperoxidase (MPO) activity which is used as an indicator of neutrophil infiltration was significantly reduced in the SF group and the results were close to the MPO values of the control group while ulcer formation significantly increased the neutrophil infiltration in the stomach tissue and the MPO values according to the control group.

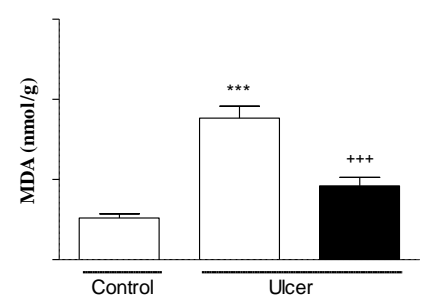

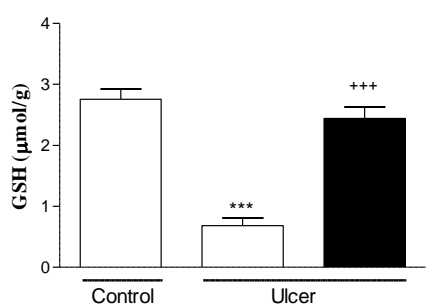

c)

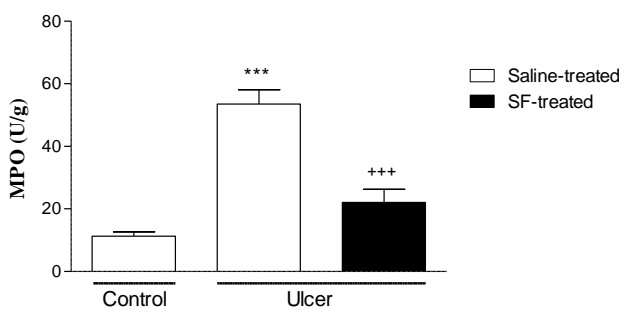

Figure 2. Serum a) Malondialdehyde (MDA), b) Glutathione (GSH) and c) Myeloperoxidase (MPO) values in the rat model of ulcers. SF; silk fibroin.

${ }^{* * *} \mathrm{p}<0.001$ Comparisons according to control group ${ }^{+++} \mathrm{p}<0.001$ Comparisons according to ulcer group.

\subsubsection{Immunoblotting}

In this study B-cell lymphoma 2 (Bcl-2) and Bcl-2-associated X protein (Bax) protein expressions were evaluated by Western blotting in order to analyze the alterations in the ratio of $\mathrm{Bcl}-2 / \mathrm{Bax}$ in apoptosis. The membranes and representative immunoblots of the stomach tissues are illustrated in Figure 3.

When the ratio of Bcl-2/Bax expression in sample tissue was examined, a significant decrease was found in the ulcer group compared to the control group and this decreased was reversed in the SF-treated ulcer group with SF application as can be seen in Figure 4a. Casp-9 expression levels in stomach tissue were significantly higher in the ulcer group than the control group as shown in Figure $4 \mathrm{~b}$ and this increase was found to be significantly inhibited in the group of ulcers treated with SF. Expression levels of casp-3 in stomach tissue were higher in the ulcer group than the control group as it is observed in casp-9 and the similar pattern is followed as casp-3 by reversing the levels to the control group with SF application as represented in Figure $4 \mathrm{~b}$ and $4 \mathrm{c}$. Ulcer formation increases expression levels of pro-apoptotic proteins; Bax, casp-3, and casp-9 in the sample tissues while decreasing the level of antiapoptotic protein; Bcl-2 expression. In the group of ulcers treated with SF a reduction in the expression levels of Bax, casp-3 and casp-9 was observed while the level of antiapoptotic protein Bcl-2 expression was increased.

\section{DISCUSSION}

Alcohol intake is coupled with the start and prolongation of gastric ulcers. The extent of gastric damage that forms as a result of noxious agents like ethanol depends upon the balance between the factors supporting this damage and those promoting the natural defense mechanisms. Epidemiologic data demonstrated that alcohol ingestion elevates both the incidence and relapse rate of peptic ulcer diseases which delays ulcer healing in humans [19]. Ethanol induces motility disorders and mucosal lesions that are dose-dependent and reversible under acute conditions. Studies showed that gastric mucosal defense mechanisms are distorted mainly by direct contact of alcohol or its metabolite acetaldehyde with the mucosa [20, 21]. 


\section{Control Saline-treated SF-treated}

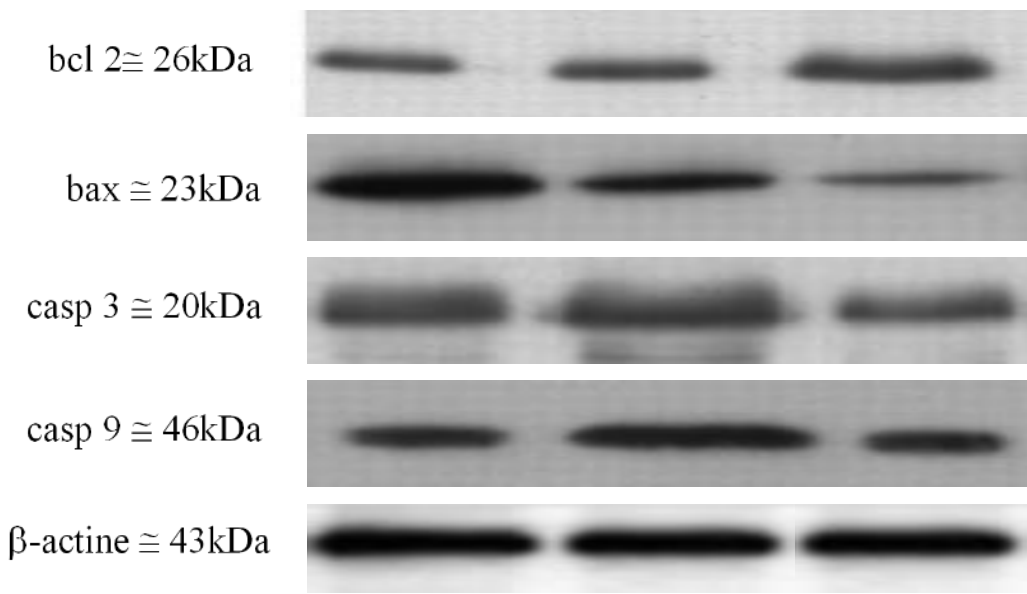

Figure 3. The representative images of nitrocellulose membranes obtained from immunoblotting experiments of stomach tissues in control, saline-treated ulcer and silk fibroin-treated ulcer groups showing protein expressions of bax, bcl 2, caspase 3 , caspase 9 and $\beta$-actin. $\beta$-actin was used to normalize the amount of protein loaded in each lane.
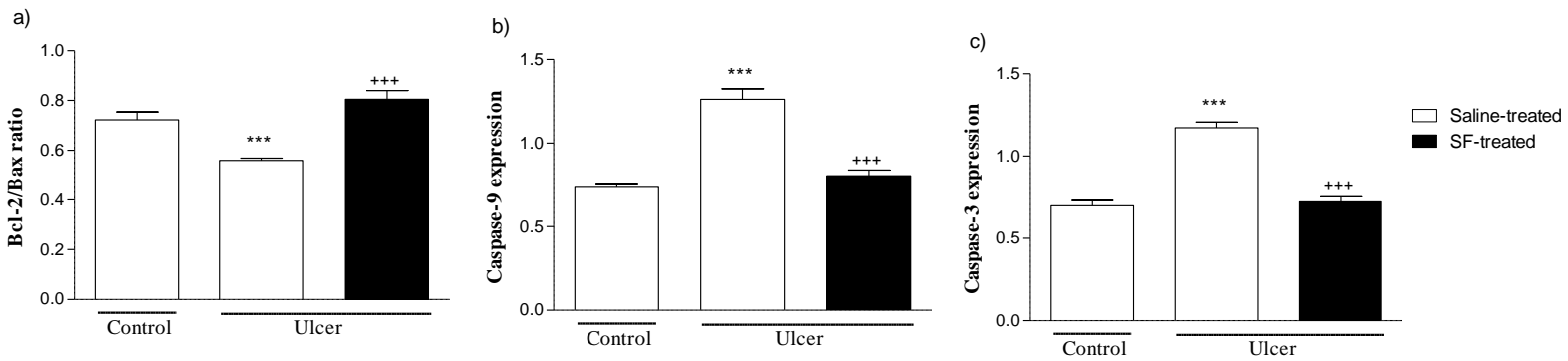

Figure 4. Expression of bcl 2 / bax, caspase-9 (casp 9) and caspase-3 (casp 3) in the tissues of all groups in the rat model of ulcer. SF; silk fibroin.

${ }^{* * *} \mathrm{p}<0.001$ Comparisons according to control group, ${ }^{+++} \mathrm{p}<0.001$ Comparisons according to ulcer group.

Since $\mathrm{EtOH}$ consumption is considered to be major risk factor in the development of gastroduodenal ulcers, it is thought that better understanding of the cellular and molecular mechanisms of injury may support the therapeutic approaches. Present study showed that all the parameters representing the presence of oxidative injury in the gastric mucosa were obviously reversed by SF treatment while ulcer healing following ethyl alcohol administration was facilitated indicating the idea that SF has powerful healingeffects on the injured stomach. Moreover, the increased levels of TNF- $\alpha$ and IL- $\beta$ in serum and the increased activity of MPO was determined in ulcer tissues. The extent of injury was also drastically decreased by SF application as analysed by macroscopic and microscopic scores and reduced MDA content.

Furthermore, experimental gastric ulcer studies revealed that the stomach and the upper gastrointestinal tract are the main sites of EtOH metabolism. The metabolism of EtOH generates superoxide radicals supporting lipid peroxidation which is known to be a mechanism of ethanol-induced gastric mucosal injury. Moreover, MDA is known to be a good indicator of the degree of lipid peroxidation [2225]. In the current study, parallel to ulcer formation, a significant elevation in MDA content was observed once ethanol given orally and also indicate that SF pretreatment significantly prevents MDA production implying the idea that reduction in lipid peroxidation and cellular injury protecting the gastric tissue against ethanol-induced oxidative damage. 
In addition to these, recent studies have revealed that reduction in GSH levels was one of the mechanisms played role in the pathogenesis of alcohol-induced gastric injury [26]. Glutathione is an important constituent of intracellular protective mechanisms against various noxious stimuli including oxidative stress. It was reported that tissue GSH levels significantly reduced due to oxidative stress allowing enhanced free radical-induced tissue damage [26]. In accordance with the previous reports, our results also demonstrated a reduction in GSH levels as observed in the alcohol-induced gastric injury which is one of the main factors allowing lipid peroxidation and subsequent tissue damage. Thus, the decrease in GSH levels in gastric tissue may be due to its consumption during the oxidative stress induced by alcohol. The intracellular GSH content is quickly used up as a result of GSH consumption by glutathione peroxidase enzyme during $\mathrm{H}_{2} \mathrm{O}_{2}$ elimination. The current findings showed that depletion of GSH level was prevented by $\mathrm{SF}$ administration.

As reactive oxygen metabolites play vital role in the pathogenesis of gastroduodenal mucosal inflammation (also in other models of mucosal damage induced by nonsteroidal anti-inflammatory drugs, ethanol or H. Pylori), peptic ulcer disease and gastric cancer, diverse regimens of reactive oxygen metabolite scavengers appear to be novel treatment strategies for upper gastrointestinal diseases. As the importance mentioned previously, primarily superoxide anions (oxygen derived free radicals), lipid peroxides and hydroxyl radicals have been found to play major role in the pathogenesis of acute experimental gastric lesions [27, 28]. Studies showed that gastric injury induced by ethanol involves toxic oxygen metabolites. Since one of the sources of oxygen radicals in gastric mucosal injury induced by EtOH in rats seems to be the neutrophils, the role of neutrophils was analysed by determining tissue-associated MPO activity which was significantly high after EtOH application [29]. Furthermore, the MPO activity which is known as a marker of neutrophil aggregation at the site of inflammation generally rises in ulcerated condition and decreases with the healing process [30]. Silk fibroin application found to prevent the increase in MPO activity significantly by restoring it to control levels indicating the idea that the neutrophil infiltration might have been inhibited by silk fibroin biomaterial. Among several cytokines, the proinflammatory TNF- $\alpha$ secreted by activated macrophages plays a vital role in controlling immune response and supporting the release of other pro-inflammatory mediators. It has a largely unique role in leukocyte movement within the inflamed tissues [31]. The current findings show that the silk fibroin suppressed the neutrophil recruitment and its major regulator TNF- $\alpha$ in the gastric tissue, which appear to be responsible for the recovery of oxidative injury in the stomach.

The current findings showed for initiation of apoptosis in ethanol induced gastric tissues there was an upregulation in caspase-3 whereas there was a decline in Bcl-2 levels. These data are compatible with previous studies showing enhanced apoptotic death of gastric epithelial cells in ethanol-induced gastric mucosal injury [32-34]. Inflammatory signals along with oxidative stress are known to cause the activation of number of genes that are responsible for cellular death by apoptosis. Apoptotic cascade is known to start by pro-apoptotic signals such as Bax which supports the release of Cytochrome-C (Cyt $\mathrm{C}$ ) from the mitochondria to the cytosol. Following the release of Cyt C, casp-9 is activated which leads to activation of casp-3. Our results demonstrated that SF application suppressed the activation of casp-9 and casp-3 dependent to pro-apoptotic Bax initiator and subsequently, the levels of anti-apoptotic Bcl-2 is elevated indicating attenuation of gastric mucosal apoptosis. The reduction of mucosal apoptosis can be explained with the observed suppression of lipid peroxidation and TNF-a. However, excessive exposure of gastric mucosa to TNF-a has been reported to enhance gastric epithelial apoptosis [34-36].

It has been demonstrated that in gastric tissues, ethanol seriously increases the low level of apoptosis which normally occurs to protect against the survival and expansion of genetically damaged cells [37, 38]. Our results showed that exposuring to ethanol increases pro-apoptotic protein expressions in gastric injury tissues. Consequently, our results highlights evidences for the protective effects of SF tretament in a rat model of ethanol-induced gastric ulcer. Meanwhile, curbing of apoptosis and downregulation of cytokines contributed to SF protection against ethanol damage. 


\section{CONCLUSION}

In conclusion, the results showed that the gastro protective effects of silk fibroin in ethanol induced oxidative damage may be because of the inhibition of lipid peroxidation by maintaining neutrophil infiltration. Thus, the current study highlights the benefits of SF as an effective and safer approach for the management of gastric ulcer.

\section{MATERIALS AND METHODS}

\subsection{Materials}

Silk fibroin was obtained from silkworms (Bombyx mori) from villages of North Cyprus. All chemicals were purchased from Sigma (St Louis, MO, USA) unless indicated.

\subsubsection{Preparation of silk fibroin (SF) aqueous solution}

Cocoons of B. mori silkworm were degummed by adding $1 \mathrm{~g}$ silk fibroin cocoons in a $0.1 \mathrm{M}$ sodium carbonate solution at $75^{\circ} \mathrm{C}$ on a hot plate stirrer at the speed of $1.5 \mathrm{rpm}$ for $30 \mathrm{~min}$ and subsequently rinsed with ultra pure distilled water. The extracted SF was dried overnight and then dissolved in $\mathrm{CaCl}_{2}$ solution in ethanol and water with molar ratio of $n_{\mathrm{C}_{2} \mathrm{H}_{5} \mathrm{OH}} n_{\mathrm{CaCl}_{2}:} n_{\mathrm{H}_{2} \mathrm{o}} ;(2: 1: 8)$ at $75^{\circ} \mathrm{C}$ under continous stirring. This aqueous silk fibroin solution was obtained by dialyzing it against deionized water using dialysis tubing for 3 days followed by filtration [39].

\subsection{Animals conditions}

Initially, an approval from the institutional ethical committee was obtained before the experimental period. In total, Wistar Albino rats $(n=18)$ weighing 200-300 g and 14-16 week old supplied from Near East University Animal Center were used. Both sexes of Wistar albino rats were kept at a constant temperature $\left(22 \pm 1^{\circ} \mathrm{C}\right)$ with $12 \mathrm{~h}$ light and dark cycles and were fed ad libitum with standardized rat chow.

\subsection{Experimental design}

For 3 consecutive days, orogastrically either SF $(600 \mathrm{mg} / \mathrm{kg})$ or saline were given to rats. On the $4^{\text {th }}$ day, animals were deprived of food but allowed free access to water for $24 \mathrm{~h}$ before the experiment. While control groups were treated with only physiological saline, the ulcer groups were treated orally either with saline or SF. For ulcer induction $1 \mathrm{ml}$ of absolute $\mathrm{EtOH}$ by gavage were given to both saline+treated ulcer group and SF+treated ulcer group. Firstly, intracardiac blood was taken at $60 \mathrm{~min}$ of EtOH or saline administration and immediately animals were decapitated.

\subsection{Macroscopic analysis}

The freshly excised stomachs were examined macroscopically for the analysis of hemorrhagic lesions in the glandular mucosa. Directly after decapitation, stomachs were dissected out along the greater curvature and the mucosa was rinsed with cold normal saline in order to remove possible excess blood contaminant. Every $1 \mathrm{~mm}$ lesion from the samples were equal to three petechia and summed per stomach, expressing the ulcer index (UI) [40].

The proinflammatory cytokines (TNF- $\alpha$, IL1- $\beta$ ) were assayed in blood samples. Gastric tissue samples obtained from the corpus region were stored at $-80^{\circ} \mathrm{C}$ for the determination of MDA, GSH levels and MPO activity in order to examine the presence of oxidant injury. In addition to these, casp-3, casp-9 and Bcl-2, Bax expressions were determined by Western blotting method in the sample tissues.

\subsection{Serum analysis}

Serum TNF-a (BioSource Europe S.A. Catalog No.KRC 3014, Nivelles, Belgium) and IL-1 $\beta$ (ELISA, BioSource Catalog No.KRC0011, Nivelles, Belgium) levels were measured by ELISA using an enzymelinked immunosorbent assay (ELISA) kits. 


\subsection{Analysis in the tissue}

As it is described by Beuge et al., in order to measure the MDA levels, the samples of tissue were homogenized with ice-cold $150 \mathrm{mM} \mathrm{KCl} \mathrm{[41].}$

\subsubsection{Levels of GSH and MPO activity assay}

Glutathione in tissue was determined according to Ellman method [42]. The samples were centrifuged at $3000 \mathrm{rpm}$ for $15 \mathrm{~min}$ and the supernatant was discarded. The $0.5 \mathrm{ml}$ supernatant was added to $2 \mathrm{ml}$ of $0.3 \mathrm{~mol} / 1 \mathrm{Na}_{2} \mathrm{HPO}_{4} .2 \mathrm{H}_{2} \mathrm{O}$ solution. Then, $0.2 \mathrm{ml}$ solution of dithiobisnitrobenzoate $(0.4 \mathrm{mg} / \mathrm{ml}$ $1 \%$ sodium citrate) was added. After mixing, the absorbance of the resulting color was measured at $412 \mathrm{~nm}$ in the spectrophotometer. Results are expressed in $\mu \mathrm{mol} \mathrm{GSH} / \mathrm{g}$ tissue. Thiobarbituric acid reactive substances solution was added on the homogenate. The samples were allowed to cool for $15 \mathrm{~min}$ at room temperature after being left in the boiling water bath. The tissue was centrifuged at $3000 \mathrm{rpm}$ for $10 \mathrm{~min}$ and the color absorbance of the upper phase was read at $532 \mathrm{~nm}$ on a spectrophotometer.

MPO activity in the tissue was determined by Hillegeas method [43]. The supernatant was discarded and then the specimens were re-homogenized by adding $0.5 \%$ Hexadecyltrimethyl-ammonium bromide. The supernatant were frozen 3 times with sonication following centrifugation at $41400 \times \mathrm{g}$ for $10 \mathrm{~min}$ at a temperature of $4^{\circ} \mathrm{C}$. $0.3 \mathrm{ml}$ of the supernatant was added to $2.3 \mathrm{ml}$ of reaction mixture containing $50 \mathrm{mM}$ Phosphate Buffer, o-dianisidine and $20 \mathrm{mM} \mathrm{H}_{2} \mathrm{O}_{2}$ solution. MPO activity that is expressed as $\mathrm{U} / \mathrm{g}$ in tissue was determined as the absorbance of the resulting color was measured at $460 \mathrm{~nm}$ for $3 \mathrm{~min}$.

\subsubsection{Preparation of tissue and immunoblotting}

For the molecular analysis of the tissues, $20 \mathrm{mM}$ Tris buffer $\mathrm{pH}=7.4$ containing protease inhibitor $(0.2 \mathrm{mM}$ PMSF, $1 \mu \mathrm{M}$ pepstatin, $1 \mu \mathrm{g} / \mathrm{ml}$ leupeptin and $10 \mu \mathrm{g} / \mathrm{ml}$ soybean trypsin), $10 \%$ glycerol, $50 \mathrm{mM} \mathrm{NaCl}$, $2 \mathrm{mM}$ DTT and $1 \mathrm{mM}$ EDTA was added into the tissues and homogenized for 90s. After, the homogenates were centrifuged at $2000 \times \mathrm{g}$ for $10 \mathrm{~min}$, the supernatant was centrifuged again at $12.000 \times \mathrm{g}$ for $60 \mathrm{~min}$. The obtained supernatant fraction was centrifuged again at $12.000 \times \mathrm{g}$ for $1 \mathrm{~s}$ to obtain the cytoplasmic fraction. Pellets were incubated with $50 \mathrm{mM}$ Tris- $\mathrm{HCl}$ (p.H: 7.4), 5\% glycerol, $1 \mathrm{mM}$ EDTA, $5 \mathrm{mM}$ DTT, protease inhibitors and $0.05 \%$ Triton X-100 for 90 min vortexing and used as mitochondrial extract. All these operations are done at $+4{ }^{\circ} \mathrm{C}$. The protein content of the samples was determined by the Lowry method [44]. Cytoplasmic extractions were used to determine Bax, casp-3 and -9 expression levels whereas mitochondrial extractions were used to determine Bcl-2 expression level. Samples including $100 \mu \mathrm{g}$ protein were run on gel electrophoresis containing $12 \%$ sodium dodecyl sulfate-polyacrylamide (SDS-PAGE) and transferred onto nitrocellulose membranes (Schleicher and Schuell, $0.45 \mu \mathrm{m}$, Germany) for $90 \mathrm{~min}$ at $80 \mathrm{~V}$. The membranes were blocked with Tris buffered saline containing 1\% BSA 0.05\% Tween 20 (TBS-T) and 1\% BSA buffer for $1 \mathrm{~h}$. After blocking, the membranes were incubated overnight with polyclonal primary antibodies. [Bcl-2 (1:200), Bax (1: 200), casp-3 (1:100), or casp-9 (1: 100)] for $14 \mathrm{~h}$ at $+4^{\circ} \mathrm{C}$. Immunoblots were standardised according to expression of $\beta$-actin (1:200) for all the membranes. All antibodies were supplied by Santa Cruz Biotechnology, Inc. (Santa Cruz, CA, USA). All chemicals were purchased from Sigma.

After each incubation, the membranes were incubated with alkaline phosphatase-conjugated rabbit monoclonal anti-goat IgG secondary antibodies for $1 \mathrm{~h}$ at $20^{\circ} \mathrm{C}$ and then washed with TBS-T three times for $15 \mathrm{~min}$. The antibody-antigen complex was observed with NBT/ BCIP. The densitometric analyses were carried out with Bio-Rad Molecular Analyst software (free edition, www.totallab.com). Molecular weights for Bcl-2, Bax, casp-3, casp-9 and $\beta$-actin are $26 \mathrm{kDa}, 23 \mathrm{kDa}, 20 \mathrm{kDa}, 46 \mathrm{kDa}$ and $43 \mathrm{kDa}$, respectively.

\subsection{Statistics}

Statistical analysis was performed using GraphPad Prism 3.0 (GraphPad Software, San Diego; CA; USA). All data were expressed as means \pm SEM. Groups of data were compared with an analysis of variance (ANOVA) followed by Tukey's multiple comparison tests. Values of $p<0.05$ were assumed as statistically significant. 
Acknowledgements: This work was supported by Experimental Health Sciences Research Centre through Near East University (Grant numbers SAG-2014-009) and was presented at EMBO (6-8 March 2017, Groningen, Netherlands).

Author contributions: Concept - A.A., A.O.Ş.; Design - A.A., A.O.Ş.; Supervision -A.A.; Resource -A.A.; Materials - A.A., B.K., A.O.Ş.; Data Collection and/or Processing - A.A., B.K., A.O.Ş.; Analysis and/or Interpretation - A.A., B.K., A.O.Ş.; Literature Search -A.A., B.K., A.O.Ş.; Writing - A.A., B.K.; Critical Reviews - A.A., B.K., A.O.Ş.

Conflict of interest statement: The authors reports no conflict of interest in this work. The authors alone are responsible for the content and writing of the paper.

\section{REFERENCES}

[1] Tarnawski AS. Cellular and molecular mechanisms of gastrointestinal ulcer healing. Dig Dis Sci. $2005 ; 50$ (Suppl 1): 24-33.

[2] Taupin D, Wu DC, Jeon WK, Devaney K, Wang TC, Podolsky DK. The trefoil gene family are coordinately expressed immediate-early genes: EGF receptor-and MAP kinase-dependent interregulation. J Clin Invest. 1990; 103: 31-38.

[3] Wong WM, Playford RJ, Wright NA. Peptide gene expression in gastrointestinal mucosal ulceration: ordered sequence or redundancy? Gut. 2000; 46: 286-292.

[4] Günal O, Oktar BK, Ozçinar E, Sungur M, Arbak S, Yeğen B. Estradiol treatment ameliorates acetic acid-induced gastric and colonic injuries in rats. Inflammation. 2003; 27: 351- 359.

[5] Okabe S, Amagase K. An overview of acetic acid ulcer models the history and state of the art of peptic ulcer research. Biol Pharm Bull. 2005;28: 1321-1341.

[6] Upadhyay NK, Kumar R, Mandotra Sk, Meena RN, Siddiqui MS, Sawhney RC. Safety and healing efficacy of Sea Buckthorn (Hippophaerhamnoides L.) Food Chem Toxicol. 2009; 47: 1146-1153.

[7] Singer AJ, Berruti L, Thode Jr HC, and McClain SA. Standardized burn model using a multiparametric histologic analysis of burn depth. Acad Emerg Med. 2000; 7: 1-6.

[8] Gurfinkel R, Singer AJ, Cagnano E, and Rosenberg L. Development of a novel animal burn model using radiant heat in rats and swine. Acad Emerg Med. 2010; 17: 514-520.

[9] Arthurson G. Pathophysiology of the burn wound and pharmacological treatment. Burn. 1996; 22: 255-274.

[10] Horan RL, Antle K, Collette AL, Huang YZ, Huang J, Moreau JE, Volloch V, Kaplan DL, Altman GH. In vitro degradation of silk fibroin. Biomaterials. 2005; 26: 3385-3393. doi: 10.1016/j.biomaterials.2004.09.020

[11] Meinel L, Hofmann S, Karageorgiou V, Kirker-Head C, McCool J, Gronowicz G, Zichner L, Langer R, VunjakNovakovic G, Kaplan DL. The inflammatory responses to Silk films in vitro and in vivo. Biomaterials. 2005; 26: 147155.

[12] Mori H, and Tsukada M. New silk protein: modification of silk protein by gene engineering for production of biomaterials. Rev Mol Biotechnol. 2000; 74: 95-103.

[13] Mauney JR, Nguyen T, Gillen K, Kirker-Head C, Gimble JM, and Kaplan DL. Engineering adipose-like tissue in vitro and in vivo utilizing human bone marrow and adipose-derived mesenchymal stem cells with silk fibroin $3 \mathrm{D}$ scaffolds. Biomaterials. 2007; 28: 5280-5290.

[14] Minoura N, Tsukada M, and Nagura M. Fine structure and oxygen permeability of silk fibroin membrane treated with methanol. Polymer. 1990; 31: 265-269.

[15] Minoura N, Aiba S, Higuchi M, Gotoh Y, Tsukada M, and Imai Y. Attachment and growth of fibroblast cells on silk fibroin. Biochem Biophys Res Commun. 1995; 208: 511-516.

[16] Gil ES, Panilaitis B, Bellas E, and Kaplan DL. Functionalized silk biomaterials for wound healing. Adv Healthcare Mater. 2013; 2: 206-217. 
[17] Zhang W, Chen L, Chen J, Wang L, Gui X, Ran J, Xu G, Zhao H, Zeng M, Ji J, Qian L, Zhou J, Ouyang H and Zou X. Silk fibroin biomaterial shows safe and effective wound healing in animal models and a randomized controlled clinical trial. Adv Healthcare Mater. 2017; 6: 1700121-1700137.

[18] Jua HW, Leea OL, Leea JM, Moona BM, Parka HJ, Parka YR, Leea MC, Kima SH, Chaob JR, Kic CS, Park CH. Wound healing effect of electrospun silk fibroin nanomatrix in burn-model. Int J Biol Macromol. 2016; 85: 29-39.

[19] Anderson IB, Jorgensen T, Bonnevie O, Gronbaek M, Sorensen TI. Smoking and alcohol intake as risk factors for bleeding and preforated peptic ulcers; a population-based cohort study. Epidemiology. 2000; 11: 434-439.

[20] Siegmund SV, Singer MV. Effects of alcohol on the upper gastrointestinal tract and the pancreas an up-to-date overview. Z Gastroenterol. 2005; 43:723-736.

[21] Loguercio C, Taranto D, Beneduce F, del Vecchio Blanco C, de Vincentiis A, Nardi G, Romano M. Glutathione prevents ethanol induced gastric mucosal damage and depletion of sulfhydryl compounds in humans. Gut. 1993; 34:161-165.

[22] Chen SH, Liang YC, Chao JC, Tsai LH, Chang CC, Wang CC, Pan S. Protective effects of Ginkgo biloba extract on the ethanol-induced gastric ulcer in rats. World J Gastroenterol. 2005; 11:3746-3750.

[23] Fan TY, Feng QQ, Jia CR, Fan Q, Li CA, Bai XL. Protective effect of Weikang decoction and partial ingredients on model rat with gastric mucosa ulcer. World J Gastroenterol. 2005; 11:1204-1209.

[24] Bafna PA, Balaraman R. Anti-ulcer and antioxidant activity of DHC-1, a herbal formulation. J Ethnopharmacol. 2004; 90:123-127.

[25] Jaarin K, Renuvathani M, Nafeeza MI, Gapor MT. Effect of palm vitamin E on the healing of ethanol-induced gastric injury in rats. Int J Food Sci Nutr. 2000; 51: 31-41.

[26] La Casa C, Villegas I, Alarcon de la Lastra C, Motilva V, Martin Calero MJ. Evidence for protective and antioxidant properties of rutin, a natural flavone, against ethanol induced gastric lesions. J Ethnopharmacol. 2000; 71:45-53.

[27] Yoshikawa T, Naito Y, Kishi A, Tomii T, Kaneko T, linuma S, Ichikawa H, Yasuda M, Takahashi S, Kondo M. Role of active oxygen, lipid peroxidation, and antioxidants in the pathogenesis of gastric mucosal injury induced by indomethacin in rats. Gut. 1993; 34: 732-737.

[28] Das D, Banerjee RK. Effect of stress on the antioxidant enzymes and gastric ulceration. Mol Cell Biochem. 1993; 125:115-125.

[29] Vazquez-Ramirez R, Olguin-Martinez M, Kubli-Garfias C, Hernandez-Munoz R. Reversing gastric mucosal alterations during ethanol-induced chronic gastritis in rats by oral administration of Opuntia ficus-indica mucilage. World J Gastroenterol. 2006; 12: 4318-4324.

[30] Souza MH, Lemos HP, Oliveira RB, Cunha FQ. Gastric damage and granulocyte infiltration induced by indomethacin in tumour necrosis factor receptor 1 (TNF-R1) or inducible nitric oxide synthase (iNOS) deficient mice. Gut. 2004; 53: 791-796.

[31] Sedgwick JD, Riminton DS, Cyster JG, Korner H. Tumor necrosis factor: a master-regulator of leukocyte movement. Immunol Today. 2000; 21: 110-113.

[32] Ye HH, Wu KJ, Fei SJ, Zhang XW, Liu HX, Zhang JL, Zhang YM. Propofol participates in gastric mucosal protection through inhibiting the toll-like receptor-4/nuclear factor kappa-B signaling pathway. Clin Res Hepatol Gastroenterol. 2013; 37(1): 3-15.

[33] Yamamoto S, Watabe K, Araki H, Kamada Y, Kato M, Kizu T, Kiso S, Tsusui S, Tsujii M, Kihara S, Funahashi T, Shimomura I, Hayashi N, Takehara T. Protective role of adiponectin against ethanol-induced gastric injury in mice. Am J Physiol Gastrointest Liver Physiol. 2012; 302(8): 773-780.

[34] Al Batran R, Al-Bayaty F, Jamil Al-Obaidi MM, Abdualkader AM, Hadi HA, Ali HM, Abdulla MA. In vivo antioxidant and antiulcer activity of Parkia speciosa ethanolic leaf extract against ethanol-induced gastric ulcer in rats. PLoS One. 2013; 8(5): e64751.

[35] Mei X, Xu D, Xu S, Zheng Y. Novel role of Zn(II)-curcumin in enhancing cell proliferation and adjusting proinflammatory cytokine-mediated oxidative damage of ethanol-induced acute gastric ulcers. Chem Biol Interact. 2012; 197(1): 31-39. 
[36] Abdelwahab SI. Protective mechanism of gallic acid and its novel derivative against ethanol-induced gastric ulcerogenesis: Involvement of immunomodulation markers, Hsp70 and Bcl-2-associated X protein. Int Immunopharmacol. 2013; 16(2): 296-305.

[37] Chattopadhyay I, Nandi B, Chatterjee R, Biswas K, Bandyopadhyay U, Banerjee RK. Mechanism of antiulcer effect of Neem (Azadirachta indica) leaf extract: effect on $\mathrm{H}+-\mathrm{K}+-$ ATPase, oxidative damage and apoptosis. Inflammopharmacology. 2004; 12:153-176.

[38] Bagchi D, Carryl OR, Tran MX, Bagchi M, Vuchetich PJ, Krohn RL, Ray SD, Mitra S, Stohs SJ. Protection against chemically-induced oxidative gastrointestinal tissue injury in rats by bismuth salts. Dig Dis Sci. 1997; 42: 1890-900.

[39] Rodriguez-Nogales A, Lozano-Pérez AA, Aznar-Cervantes SD, Algieri F, Garrido-Mesa J, Garrido-Mesa N, Vezza T, Utrilla MP, Cenis JL, Rodríguez-Cabezas ME, Gálvez J. Effect of aqueous and particulate silk fibroin in a rat model of experimental colitis. Int J Pharm. 2016; 511: 1-9.

[40] Karakoyun B, Yüksel M, Ercan F, Erzik C, Yeğen BC. Alpha-lipoic acid improves acetic acid-induced gastric ulcer healing in rats. Inflammation. 2009; 32(1):37-46.

[41] Beuge JA, Aust SD. 1978. Microsomal lipid peroxidation. Methods Enzymol. 1978; 53: 302-311.

[42] Beutler E. Reduced Glutathione (GSH). Red Blood Cell Metabolism: A Manual of Biochemical Methods, Bergmeyen HV, 2nd edn., Grune and Stratton, New York, USA, 1975, pp.112-114.

[43] Hillegass LM, Griswold DE, Brickson B, and Albrightson-Winslow C. Assessment of myeloperoxidase activity in whole rat kidney. J Pharmacol Methods. 1990; 24: 285-295.

[44] Lowry OH, Rosebrough NJ, Farr AL, and Randall RJ. Protein measurement with the Folin-Phenol reagents. J Biol Ther 1951; 119: 33-43.

This is an open access article which is publicly available on our journal's website under Institutional Repository at http://dspace.marmara.edu.tr. 